\title{
Current status of pulmonary arterial hypertension in Korea
}

\author{
Albert Youngwoo Jang ${ }^{1,2}$ and Wook-Jin Chung ${ }^{1,2}$
}

\author{
${ }^{1}$ Gachon Cardiovascular Research \\ Institute, Gachon University, \\ Incheon; ${ }^{2}$ Department of \\ Cardiovascular Medicine, Gachon \\ University Gil Medical Center, \\ Incheon, Korea
}

Received: June 3, 2019

Accepted: June 14, 2019

\section{Correspondence to}

Wook-Jin Chung, M.D.

Department of Cardiovascular Medicine, Gachon University College of Medicine, 21 Namdong-daero 774beon-gil, Namdong-gu, Incheon 21565, Korea

Tel: $+82-32-460-3663$

Fax: +82-32-469-1906 E-mail: heart@gachon.ac.kr http://orcid.org/0000-00029767-7098

This paper was contributed by The Korean Society of Hypertension.
Pulmonary arterial hypertension (PAH) is characterized by remodeling of the distal pulmonary arteries resulting in high pulmonary vascular resistance and, eventually, right ventricular heart failure. Although current advances in PAH therapy have improved outcomes, poor survival remains a reality worldwide, including Korea. One of the most important issues in PAH is the late diagnosis, since screening or diagnostic efforts are often overlooked due to the rarity of disease. Data from Korean registries and observational cohorts show that delayed detection leads to increased morbidity. Additionally, low percentages of Korean patients are committed to intensive PAH-targeted therapy. Current Korean health insurance policies' lack of coverage for new PAH-targeted drugs and upfront combination therapy may also hamper the improvement of treatment outcomes. Understanding individual variability in response to therapeutics through deep phenotyping is a novel strategy that should be considered when treating PAH. Overall, early detection of PAH by proactive screening together with early, intensive, individualized PAH therapy using deep phenotyping is crucial for improving prognoses for PAH patients in Korea.

Keywords: Pulmonary arterial hypertension; Early diagnosis; Pharmacotherapy; Phenotyping; Precision medicine

\section{INTRODUCTION}

Pulmonary arterial hypertension $(\mathrm{PAH})$ is a disease with elevated mean pulmonary arterial pressure (mPAP) and pulmonary vascular resistance that eventually results in right ventricular heart failure [1-6]. Over the past two decades, there have been great advances in $\mathrm{PAH}$ treatment due to the advent of targeted therapies modulating the three classical pathophysiological pathways: the nitric oxide (NO), endothelin, and prostacycline pathways. However, poor prognoses for PAH patients remain a reality despite advances in treatment [7-13]. In addition, late detection and poor governmental support for aggressive, targeted therapy have constituted an obstacle for effectively treating this disease [10,12,14,15]. In this article, we review past and current challenges as well as future directions in the treatment of PAH in Korea.

\section{EARLY INITIATIVES FOR A NATION-WIDE PAH REGISTRY}

Due to the rarity of $\mathrm{PAH}$, nation-wide efforts to document PAH characteristics among Koreans were not made until the late 200os. Several single-center studies were published showing better prognoses for idiopathic PAH (IPAH) patients with vasoreactivity and target- 
Table 1. Comparisons of demographic, clinical, and hemodynamic characteristics in world registries of pulmonary arterial hypertension

\begin{tabular}{|c|c|c|c|c|c|}
\hline Characteristic & REVEAL 2010 & French 2006 & Spain 2012 & China 2011 & Korea 2011 \\
\hline No. of case & 2,525 & 674 & 866 & 956 & 625 \\
\hline Age, yr & $50 \pm 14$ & $50 \pm 15$ & $45 \pm 17$ & $36 \pm 13$ & $48 \pm 16$ \\
\hline Female sex, \% & 80 & 65 & 71 & 70 & 80.5 \\
\hline WHO III/IV, \% & 56 & 75 & 69 & 54 & 48.7 \\
\hline 6MWD, m & $366 \pm 126$ & $329 \pm 112$ & $382 \pm 117$ & $353 \pm 127$ & $372 \pm 123$ \\
\hline mPAP, mmHg & $51 \pm 14$ & $55 \pm 15$ & $54 \pm 16$ & $63 \pm 15$ & $66 \pm 22$ \\
\hline PVRI, wood $\mathrm{U} \times \mathrm{m}^{2}$ & $21 \pm 13$ & $21 \pm 10$ & NA & $25 \pm 14$ & $10 \pm 6$ \\
\hline
\end{tabular}

Values are presented as mean \pm SEM. Reprinted from Chung et al. [9].

WHO, World Health Organization; 6MWD, 6-minute walking distance; mPAP, mean pulmonary artery pressure; PVRI, pulmonary vascular resistance index.

ed therapy [16-18]. The advent of targeted therapies, however, imposed the need to develop a nation-wide approach to oversee and manage $\mathrm{PAH}$ patients. Accordingly, four academic societies in Korea (The Korean Society of Cardiology, The Korean Academy of Tuberculosis and Respiratory Diseases, The Korean College of Rheumatology, and The Korean Pediatric Heart Society) collaborated to design a joint registry for PAH patients in Korea. The Korean Registry of Pulmonary Arterial Hypertension (KORPAH) enrolled 625 patients (328 patients previously diagnosed [prevalent] and 297 patients newly diagnosed [incident]) between 2008 to 2011 across 35 tertiary centers [9].

\section{DEMOGRAPHICS AND ETIOLOGY OF KOREAN PATIENTS}

For the total patient population enrolled in KORPAH, either incident or prevalent, $80.5 \%$ of PAH patients were women and the mean age at enrollment was 47.6 \pm 15.7 years [9]. The percentages of congenital heart disease-related $\mathrm{PAH}$ (CHD-PAH), connective tissue disease-related $\mathrm{PAH}$ (CTD-PAH), and heritable $\mathrm{PAH}$ (HPAH) were $25.4 \%, 49.8 \%$, and $23.2 \%$, respectively, among the total cohort [9]. The proportion of patients diagnosed with right heart catheterization (RHC) was $40 \%$. For incident patients who were first diagnosed during the enrollment period, the mean age was 50.0 \pm 16.6 years and $78.5 \%$ were female [9]. Interestingly, up to $57.6 \%$ of the incident population had CTD-PAH.
Authors explained this high percentage by the possible overestimation of mPAP for CTD-PAH patients being evaluated by echocardiography and not RHC [9]. The baseline demographic, clinical, and hemodynamic properties were similar to those registries from the USA, France, Spain, and China as shown in Table 1 [8,9,11-13]. The proportion of patients with New York Heart Association (NYHA) class III/IV heart failure was $48.7 \%$, which was lower than other international registries, probably due to the aggressive screening procedures for the CTD-PAH population during enrollment (Table 1) [19].

\section{PAH THERAPY AND SURVIVAL}

Among the 297 patients who were first diagnosed during the 2008 to 2011 enrollment, only $61.3 \%$ of patients were treated by $\mathrm{PAH}$-specific medical therapies [9]. Of those, 154 patients (84.6\%) received single medications (Table 2). Strikingly, only 28 patients (15.4\% of the patients on $\mathrm{PAH}$-specific therapy) received combination therapy, a mere $9.4 \%$ of the newly diagnosed population [9]. The mean time to follow-up was 1.7 years among the 297 incident cases, and 35 mortalities occurred [9]. The cumulative patient survival is shown in Fig. 1A. The 1-, 2-, and 3-year cumulative survival rates were $90.8 \%, 87.8 \%$, and $84.4 \%$, respectively [9]. The 3-year survival rate was relatively high compared to other registries, probably due to the low percentage of NYHA III/IV heart failure patients at enrollment (Table 
Table 2. PAH-specific medications of Korean Registry of Pulmonary Arterial Hypertension in all patients and incident patients

\begin{tabular}{|lcc}
\hline Medication & $\begin{array}{c}\text { Treatments in all patients } \\
(\mathrm{n}=626)\end{array}$ & $\begin{array}{c}\text { Treatments in } \\
\text { incidence cases }(\mathrm{n}=297)\end{array}$ \\
\hline No. (\%) of patients receiving PAH-specific medications in all treatments & $380(60.8)$ & $182(61.3)$ \\
\hline No. (\%) of medications in all PAH-specific treatments & & $93(51.1)$ \\
\hline Single bosentan & $155(40.9)$ & $21(11.6)$ \\
\hline Single sildenafil & $45(11.8)$ & $17(9.3)$ \\
\hline Single inhaled ilprost & $22(5.8)$ & $23(12.6)$ \\
\hline Single beraprost & $86(22.6)$ & $28(15.4)$ \\
\hline Combinations of above single medications & $72(18.9)$ & \\
\hline
\end{tabular}

Values are presented as number (\%). Reprinted from Chung et al. [9].

$\mathrm{PAH}$, pulmonary arterial hypertension.
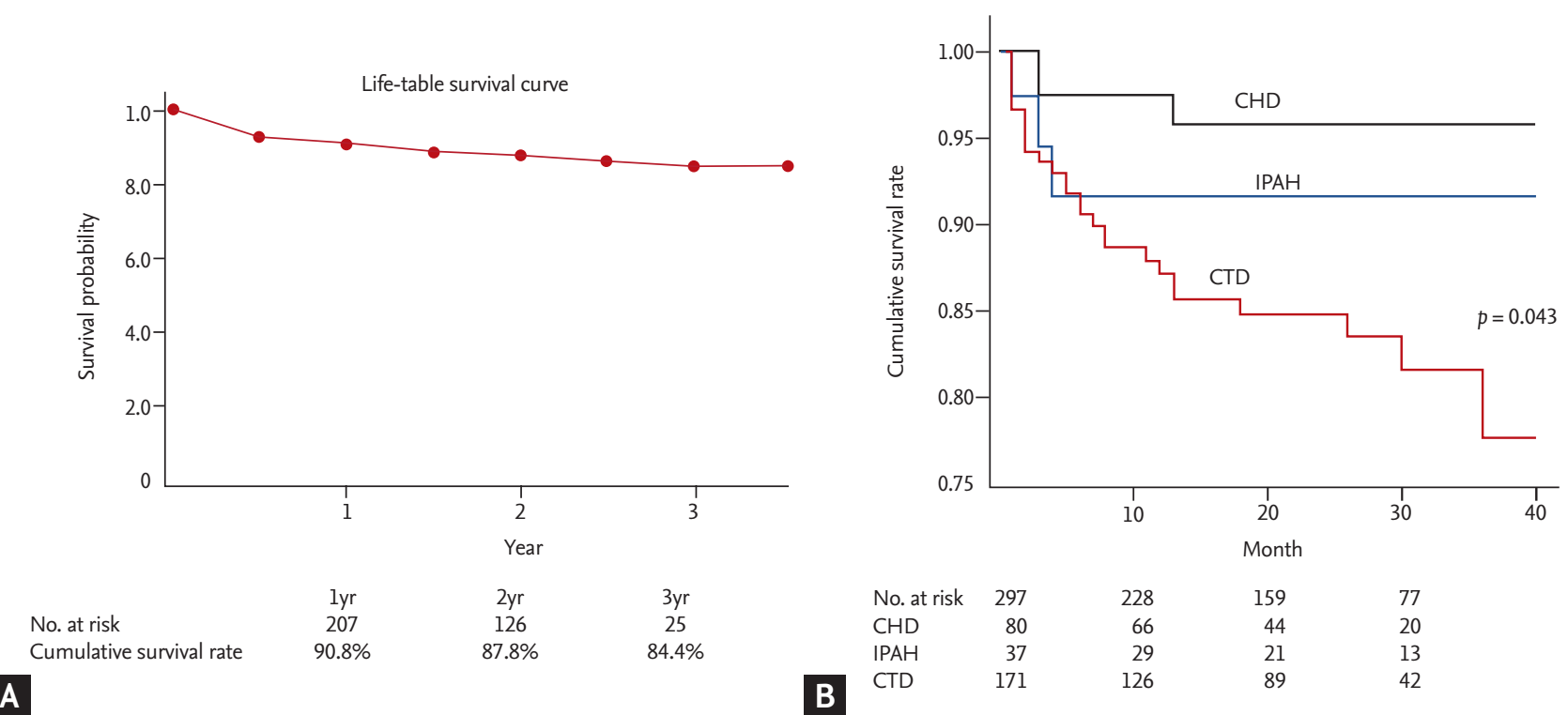

A

B

$\begin{array}{lrrrl}\text { No. at risk } & 297 & 228 & 159 & 77 \\ \text { CHD } & 80 & 66 & 44 & 20 \\ \text { IPAH } & 37 & 29 & 21 & 13 \\ \text { CTD } & 171 & 126 & 89 & 42\end{array}$

Figure 1. Cumulative survival and comparison of survival among etiologies. (A) Cumulative survival curve of the incident cases in the Korean Registry of Pulmonary Arterial Hypertension (KORPAH; $\mathrm{n}=297$ ). The 1st-, 2nd- and 3rd-year estimated survival rates were $90.8 \%, 87.8 \%$, and $84.4 \%$, respectively. (B) Comparison of survival according to the etiologies of pulmonary arterial hypertension $(\mathrm{PAH})$ of the incident cases in the KORPAH $(\mathrm{n}=297)$. This figure presents a comparison of prognoses according to the etiologies of PAH. PAH with connective tissue disease (CTD) corresponded to the highest mortality (18.8\%), followed by idiopathic PAH (IPAH) (8.1\%), and PAH with congenital heart disease (CHD; $3.9 \%)(p=0.043)$.

1) $[9,19]$. Fig. $1 B$ shows that patients with CHD-PAH had the highest survival rate $(p=0.043)$, followed by IPAH and CTD-PAH, which were consistent with the findings of other studies $[9,20,21]$.

Interestingly, when survival data of a Korean single-center study were analyzed based on initial World Health Organization (WHO)-NYHA class, an incremental decrease in survival was noted along with increasing WHO-NYHA class $(p=0.041)$, as shown in Fig. 2A [18]. The survival data were additionally analyzed in terms of the type of treatment (Fig. 2B), where targeted therapy showed significantly improved survival compared with conventional therapy $(p=0.021)$ [18]. 

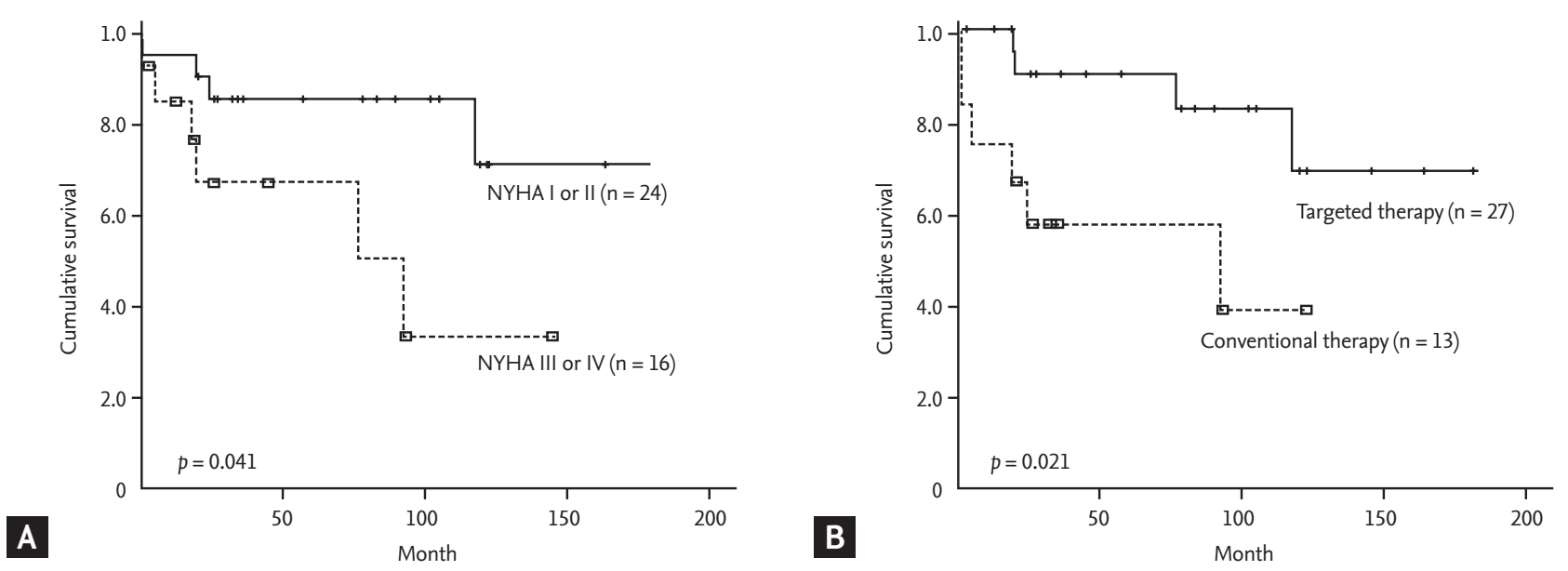

Figure 2. Comparison of survival based on initial symptom severity and type of therapy. (A) Median overall survival time of patients based on New York Heart Association (NYHA) functional classification, where patients with NYHA class I or II at the time of diagnosis showed significantly better survival than those with a more severe functional class. (B) Median overall survival time of patients according to the treatment is shown. Patients with molecular targeted therapy showed significantly better survival than those with conventional therapy only.

\section{HEALTH INSURANCE DATA FOR PAH IN KOREA}

Health insurance data on the epidemiology of PAH in Korea were also analyzed [22]. Data from 2008 to 2016 were analyzed based on International Classification of Diseases (ICD) codes, and a total of 1,307 new patients were diagnosed during this period. Similar to the KORPAH data, the mean age was $44 \pm 12$ years and 69.3\% were women [22]. IPAH was defined as patients with pulmonary hypertension (ICD codes I27.0 and I27.2) who did not have ICD codes for other underlying diseases such as left-sided heart disease, CTD-PAH, CHD-PAH, human immunodeficiency virus, schistosomiasis, or chronic hemolytic anemia [22]. IPAH was the most common diagnosis (51.6\%) in the pulmonary hypertension population, followed by CHD-PAH (25.8\%), and CTD-PAH (17.2\%) [22]. Bosentan monotherapy was the most frequently prescribed treatment [22]. Consistent with the findings of the KORPAH registry, only $18.4 \%$ of patients received combination therapy, among which a combination of bosentan and beraprost was most common (32.9\% of all combination therapies) $[9,22]$. The 3- and 5-year survival rates were $54 \%$ and $46 \%$, respectively [22]. This is significantly lower compared to the KORPAH registry data, where the 3-year survival rate was $84.4 \%$ [9]. The actual 3-year survival of Korean PAH patients may lie between $54 \%$ and $84.4 \%$, as other modern registry data have shown a 3-year sur- vival between $60 \%$ and $70 \%$ [19].

\section{LESSONS FROM KORPAH AND OTHER CO- HORTS}

The key messages that we have learned from Korean cohorts were: (1) the low performance rate of RHC may contaminate data, and (2) early detection and targeted therapy show better overall survival. The current trend in PAH therapy points to early, aggressive, combination therapy in patients with high risk symptoms $[1,23,24]$. Although the KORPAH did not stratify patients via a risk assessment, worse outcomes were associated with patients with severe symptoms (Fig. 2A) and better survival was seen in patients treated with $\mathrm{PAH}$-specific therapy (Fig. 2B). This suggests that risk stratification and early combination therapy should be adopted in the future $[1,18,23,24]$.

\section{GENETICS OF KOREAN PAH PATIENTS}

A family history of PAH has been shown to be associated with the onset of $6 \%$ to $10 \%$ of patients without other underlying pathology [25]. In the Korean population, heterozygous germline mutations of BMPR2, a gene encoding bone morphogenetic protein receptor type 2 , 
are highly prevalent $[26,27]$. It has recently been demonstrated that the BMPR2 mutation is the most common gene mutation in all categories of $\mathrm{PAH}$, with a $70 \%$ to $80 \%$ incidence in $\mathrm{HPAH}$ and $10 \%$ to $20 \%$ in IPAH [28]. Other identified gene mutations with a high level of incidence include EIF2AK4, TBX $4, A T P_{13} A_{3}, G D F 2, S_{17}$, $A Q P 1, A C V R L 1, S M A D 9, E N G, K C N K_{3}$, and CAV1 [29].

To identify genetic characteristics of the Korean PAH population further, a prospective, investigator-initiated, and multi-institutional cohort study named the Effect of BMPR-2 Gene Mutations on Hemodynamic Response by Iloprost Inhalation in Pulmonary Arterial Hypertension (PILGRIM) trial was conducted (NCTo1054105, clinicaltrials.gov) [30]. The primary objective of this study was to examine the prevalence of BMPR2 mutations and identify differences in hemodynamics between patients with or without BMPR2 mutations [30]. Patients diagnosed with either IPAH or HPAH were enrolled between 2010 to 2016 from 12 participating tertiary hospitals. A total of 73 patients who were thought to have IPAH were enrolled, among whom, seven patients were later identified as having HPAH. An additional 17 family members of seven HPAH patients were also enrolled [30]. Out of the 73 patients enrolled in the study, 16 patients $(21.9 \%)$ had BMPR2 mutations [30]. The prevalence of BMPR2 mutations seen in IPAH/HPAH patients is consistent with the findings of other groups [31-36].

\section{CURRENT PAH TREATMENT STRATEGIES AND FUTURE DIRECTIONS}

Over the past decade, we have seen the emergence of novel pharmacotherapeutic developments for the treatment of PAH. Drugs that target the classical PAH pathways have been validated by randomized trials. The phosphodiesterase inhibitors (PDEi) that modulate the NO pathway, endothelin receptor antagonists that inhibit the endothelin pathway, or prostacyclin analogues (PCA) that activate the prostacyclin pathway have all been shown to have clinical benefits. The most recently approved drugs, macitentan [37], riociguat [38], and selexipag [39] and their corresponding clinical trial results are summarized in Table 3. The most notable trend is the evidence-based migration to combination therapy from monotherapy in newly diagnosed patients [40]. This has been reflected in current PAH treatment guidelines that promote starting combination therapy as early as possible, especially in high risk patients.

The efficacy of combination therapy in PAH treatment has long been debated. Sequential combination refers to adding on a second $\mathrm{PAH}$-specific treatment as needed, whereas initial or upfront combination therapy indicates initiation of combination $\mathrm{PAH}$-specific therapy in treatment-naïve patients. The efficacy and safety of sequential combination therapy has been shown by many randomized clinical trials [37,41-48], and is well reflected in current guidelines $[1,4,6]$ and medical practices in Korea [9]. Although initial combination therapy has been shown to be efficacious and safe in smallscale, retrospective studies [49], there were no randomized clinical trials conducted until recently. A Study of First-Line Ambrisentan and Tadalafil Combination Therapy in Subjects With Pulmonary Arterial Hypertension (PAH) trial is the first trial to show the results of initial combination therapy in patients with $\mathrm{PAH}$ (Table 3) [40]. It showed that an initial double combination therapy of ambrisentan (10 mg) and tadalafil (40 $\mathrm{mg}$ ) once a day respectively, was superior to monotherapy or placebo. These findings were also replicated with scleroderma-associated PAH patients (Table 3) [50]. Japanese registry data have also shown a significant hemodynamic benefit with initial combination therapy over monotherapy (Table 3) [51,52]. Similar to these trends, a high dose of epoprostenol, a well-established PCA treatment for severe $\mathrm{PAH}$ patients, soon after the initiation of treatment has shown very promising results in a study by a pioneering Japanese group [53]. These results collectively suggest that initial com bination therapy together with high-dose epoprostenol may be the future direction of PAH therapy.

The PAH treatment strategies in Korea are based on monotherapy or sequential combination therapy. As Koreans and Japanese share significant ethnic similarities, it may be acceptable for Korean specialists to adopt aggressive, initial combination therapies that are suggested by Japanese medical groups [51,52]. The major obstacle to implementing such practices is that of the strict regulations instituted toward initial combination therapy by the current Korean health insurance system, which is in contrast to the situation in Japan and other 


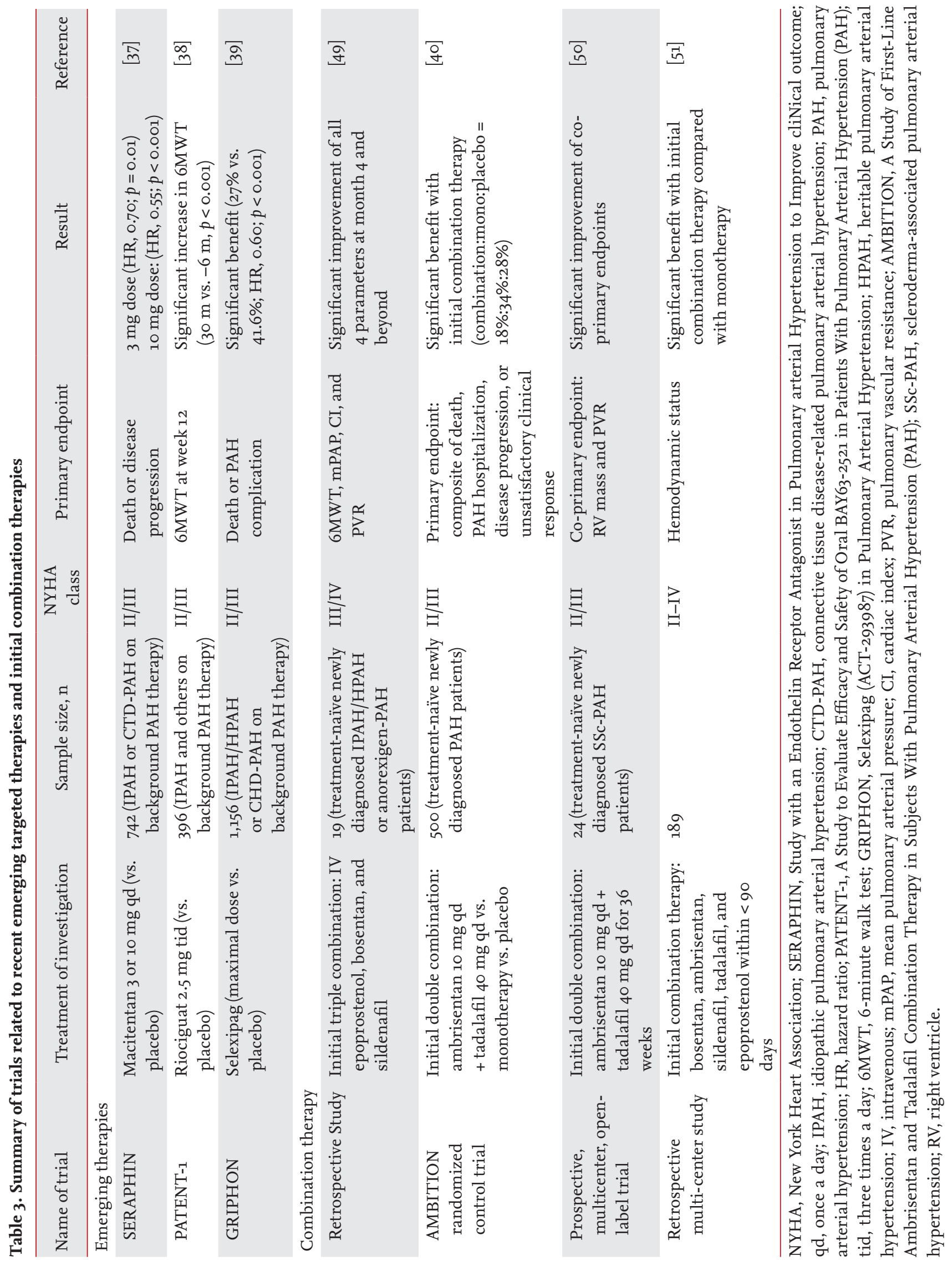


Table 4. Korean FDA approval and reimbursement by the Korean Health Insurance System for pulmonary arterial hypertension-targeted therapeutics

\begin{tabular}{|c|c|c|c|c|c|c|c|}
\hline \multirow{2}{*}{$\begin{array}{l}\text { Mechanism } \\
\text { of action }\end{array}$} & \multirow{2}{*}{ Name of drug } & \multirow{2}{*}{$\begin{array}{l}\text { Route of } \\
\text { delivery }\end{array}$} & \multirow{2}{*}{$\begin{array}{c}\text { Korean FDA } \\
\text { approval }\end{array}$} & \multirow{2}{*}{$\begin{array}{c}\text { Reimbursed by } \\
\text { NHIS }\end{array}$} & \multicolumn{3}{|c|}{$\begin{array}{l}\text { Reimbursed for NYHA } \\
\text { functional classes }\end{array}$} \\
\hline & & & & & II & III & IV \\
\hline \multirow[t]{3}{*}{ ERA } & Ambrisentan & $\mathrm{PO}$ & ० & o & $x$ & $\circ$ & $x$ \\
\hline & Bosentan & $\mathrm{PO}$ & $\circ$ & ० & $x$ & $\circ$ & ० \\
\hline & Macitentan & $\mathrm{PO}$ & $\circ$ & ० & $x$ & $\circ$ & $x$ \\
\hline \multirow[t]{3}{*}{ PDE-5 inhibitor } & Sildenafil & $\mathrm{PO}$ & ० & ० & $\circ$ & $\circ$ & $x$ \\
\hline & Tadalafil & $\mathrm{PO}$ & $x$ & $x$ & $x$ & $x$ & $x$ \\
\hline & Vardenafil & $\mathrm{PO}$ & $x$ & $x$ & $\times$ & $x$ & $x$ \\
\hline \multirow{9}{*}{$\begin{array}{l}\text { Prostacyclin } \\
\text { analogues }\end{array}$} & Epoprostenol & IV & $x$ & $x$ & $\times$ & $x$ & $\times$ \\
\hline & Iloprost & INH & $\circ$ & ० & $\times$ & $\circ$ & $\circ$ \\
\hline & & IV & $x$ & $x$ & $\times$ & $x$ & $x$ \\
\hline & Treprostinil & $\mathrm{SC}$ & $\circ$ & ० & $\times$ & $\circ$ & $\circ$ \\
\hline & & $\mathrm{INH}$ & $x$ & $x$ & $\times$ & $x$ & $x$ \\
\hline & & IV & $\circ$ & ० & $\times$ & $\circ$ & $\circ$ \\
\hline & & $\mathrm{PO}$ & $x$ & $x$ & $\times$ & $x$ & $x$ \\
\hline & Beraprost & $\mathrm{PO}$ & ○ & ० & \multicolumn{3}{|c|}{ No clear criteria } \\
\hline & Selexipag & $\mathrm{PO}$ & $\circ$ & $\circ$ & $\times$ & $\circ$ & $x$ \\
\hline sGC stimulator & Riociguat & $\mathrm{PO}$ & 0 & $x$ & $\times$ & $x$ & $x$ \\
\hline
\end{tabular}

FDA, Food and Drug Administration; NHIS, National Health Insurance Service; NYHA, New York Heart Association; ERA, endothelin receptor antagonist; PO, per oral; PDE-5, phosphodiesterase 5; IV, intravenous; INH, inhaled; SC, subcutaneous; sGC, soluble guanylyl cyclase.

countries where regulations are less strict $[4,54]$. Additionally, the most efficacious drug, epoprostenol, is currently not marketed in Korea, which limits the options for early, aggressive treatment strategies (Table 4). Collaborative efforts between governmental authorities and pharmacological companies are currently underway to bring epoprostenol to Korea so that early aggressive $\mathrm{PAH}$ therapies become an available option.

\section{LIFESTYLE MODIFICATION AND BETTER SUP- PORTIVE CARE}

As patient survival has improved, lifestyle modification and better supportive care have become equally important in PAH [55] as it is the case with other chronic diseases [56-59]. Lifestyle modification and supportive care have been overlooked in PAH because it has previously been considered untreatable. Exercise-based rehabilitation has been shown to improve quality of life in PAH patients [6o]. European Society of Cardiology guidelines recommend patients consult with PAH specialists for exercise rehabilitation recommendations [1].

In PAH patients, iron levels have been shown to be decreased [61]. Although there are no randomized trial data, a single high-dose iron supplement has been suggested to be beneficial [62]. Additionally, since vitamin $\mathrm{D}$ levels are often low in PAH patients, vitamin D supplementation may also be helpful to $\mathrm{PAH}$ patients. It has been suggested that vitamin $D$ replacement can improve right ventricular size and exercise tolerance [63]. As constant supportive care and lifestyle modification are considered crucial in other chronic diseases such as heart failure or hypertension, such efforts may be necessary for favorable outcomes and quality of life for Korean patients with PAH. 


\section{EARLY DETECTION LEADS TO BETTER OUTCOMES}

It has been demonstrated that the initial diagnosis of $\mathrm{PAH}$ is often delayed, as the percentage of patients with NYHA class III/IV is up to $70 \%[12,13]$. The mean duration between symptom onset and initial diagnosis is 2 to 4 years according to registry data $[12,15,64]$. Interestingly, the French PAH registry showed that in patients initially diagnosed with $\mathrm{PAH}$ without screening, the percentage of NYHA class III/IV was much higher (75\%), as compared to their screened counterparts (44\%) [12]. Epidemiological and clinical trial data have revealed that delay of diagnosis may be one of the major causes of decreased survival [65-67]. Consistent with such findings, Korean data show that patients with less severe symptoms (NYHA class I/II) have better long-term survival [18]. Accordingly, it is crucial to detect PAH as early as possible through proactive screening. Screening tools for early detection, such as echocardiography, $\mathrm{N}$-terminal pro-brain natriuretic peptide (NT-proBNP) detection, or pulmonary function tests may be useful in patients with predisposing factors for PAH [68]. In particular, RHC should be evaluated for high NT-proBNP levels, FVC/DLCO ratio > 1.6, or abnormal echocardiographic findings in patients with systemic sclerosis [68]. Patients with human immunodeficiency virus infection, a family history of $\mathrm{PAH}$, portal hypertension, or CHD should also be proactively screened through routine echocardiography [68].

\section{INDIVIDUALIZED THERAPEUTIC STRATEGIES THROUGH DEEP PHENOTYPING}

PAH registries from Europe, North America, and Asia have provided a better understanding of the prevalence of each PAH subtype and its prognosis [9,69-72], and a high degree of phenotypic variability between IPAH and HPAH has been increasingly recognized. This phenotypic diversity has brought into question the current uniform PAH treatment strategies, regardless of individual patient characteristics, which may bring about variable treatment responses among patients [73,74]. Accordingly, it is necessary to develop better methods for predicting outcomes from the current classes of $\mathrm{PAH}$ medications. Deep phenotyping allows the acquisition of large amounts of data from gene sequencing, protein identification, and metabolic profiling [75]. For example, through gene sequencing, single nucleotide polymorphisms or mutations can be identified that are cornerstones in delineating phenotypic variability [29,76,77]. Pioneering efforts are currently being made worldwide to consolidate our understanding of phenotypic variability. The new generation of PAH registries such as the National Biological Sample and Data Repository for $\mathrm{PAH}$ [78] and the Biomedical Research Identification of Genetic Etiology of PAH (BRIDGE-PAH) [79] are actively recruiting patients in the United States and United Kingdom, respectively, and are focusing on describing deep phenotypes. These trends create an urgent need for an East Asian population-based PAH registry that incorporates deep phenotyping, including robust genetic, epigenetic, and multi-genomic level data from $\mathrm{PAH}$ patients. The PAH Platform for Deep Phenotyping in Korean Subjects (PHOENIKS) is aimed at building a database based on clinical data and biospecimens for PAH patients across South Korea (NCT03933579, Clinicaltrials.gov) [8o].

\section{CONCLUSIONS}

PAH has become a treatable disease over the last decade in Korea due to the introduction of targeted therapies. As current registry and observational studies within Korea show, proactive screening and early detection together with early aggressive combination therapy is warranted to improve survival for $\mathrm{PAH}$ patients.

\section{Conflict of interest}

No potential conflict of interest relevant to this article was reported.

\section{REFERENCES}

1. Galie N, Humbert M, Vachiery JL, et al. 2015 ESC/ERS guidelines for the diagnosis and treatment of pulmonary hypertension: the joint task force for the diagnosis and treatment of pulmonary hypertension of the European Society of Cardiology (ESC) and the European Respiratory 
Society (ERS): Endorsed by: Association for European Paediatric and Congenital Cardiology (AEPC), International Society for Heart and Lung Transplantation (ISHLT). Eur Heart J 2016;37:67-119.

2. National Pulmonary Hypertension Centres of the UK and Ireland. Consensus statement on the management of pulmonary hypertension in clinical practice in the UK and Ireland. Thorax 2008;63:ii1-ii41.

3. Maron BA, Galie N. Diagnosis, treatment, and clinical management of pulmonary arterial hypertension in the contemporary era: a review. JAMA Cardiol 2016;1:10561065 .

4. Fukuda K, Date H, Doi S, et al. Guidelines for the treatment of pulmonary hypertension (JCS 2017/JPCPHS 2017). Circ J 2019;83:842-945.

5. Galie N, McLaughlin VV, Rubin LJ, Simonneau G. An overview of the 6th World Symposium on Pulmonary Hypertension. Eur Respir J 2019;53.

6. Klinger JR, Elliott CG, Levine DJ, et al. Therapy for pulmonary arterial hypertension in adults: update of the CHEST guideline and expert panel report. Chest 2019;155:565-586.

7. Ogawa A, Satoh T, Tamura Y, Fukuda K, Matsubara H. Survival of Japanese patients with idiopathic/heritable pulmonary arterial hypertension. Am J Cardiol 2017;119:14791484 .

8. Zhang R, Dai LZ, Xie WP, et al. Survival of Chinese patients with pulmonary arterial hypertension in the modern treatment era. Chest 2011;140:301-309.

9. Chung WJ, Park YB, Jeon CH, et al. Baseline characteristics of the Korean Registry of Pulmonary Arterial Hypertension. J Korean Med Sci 2015;30:1429-1438.

10. Lim Y, Low TT, Chan SP, et al. Pulmonary arterial hypertension in a multi-ethnic Asian population: characteristics, survival and mortality predictors from a 14-year follow-up study. Respirology 2019;24:162-170.

11. Frost AE, Badesch DB, Barst RJ, et al. The changing picture of patients with pulmonary arterial hypertension in the United States: how REVEAL differs from historic and non-US Contemporary Registries. Chest 2011;139:128-137.

12. Humbert M, Sitbon O, Chaouat A, et al. Pulmonary arterial hypertension in France: results from a national registry. Am J Respir Crit Care Med 2006;173:1023-1030.

13. Escribano-Subias P, Blanco I, Lopez-Meseguer M, et al. Survival in pulmonary hypertension in Spain: insights from the Spanish registry. Eur Respir J 2012;40:596-603.
14. Fernandes CJ, Martins BC, Jardim CV, et al. Quality of life as a prognostic marker in pulmonary arterial hypertension. Health Qual Life Outcomes 2014;12:130.

15. Strange G, Gabbay E, Kermeen F, et al. Time from symptoms to definitive diagnosis of idiopathic pulmonary arterial hypertension: the delay study. Pulm Circ 2013;3:89-94.

16. Ahn JH, Kang BJ, Hong SI, et al. Clinical characteristics and survival of Korean idiopathic pulmonary arterial hypertension patients based on vasoreactivity. J Korean Med Sci 2014;29:1665-1671.

17. Kang BJ, Lee SD, Oh YM, Lee JS. Improved survival of Korean patients with idiopathic pulmonary arterial hypertension after the introduction of targeted therapies. Heart Lung 2014;43:561-568.

18. Park YM, Chung WJ, Choi DY, et al. Functional class and targeted therapy are related to the survival in patients with pulmonary arterial hypertension. Yonsei Med J 2014;55:1526-1532.

19. McGoon MD, Benza RL, Escribano-Subias P, et al. Pulmonary arterial hypertension: epidemiology and registries. $\mathrm{J}$ Am Coll Cardiol 2013;62:D51-D59.

20. Chung L, Liu J, Parsons L, et al. Characterization of connective tissue disease-associated pulmonary arterial hypertension from REVEAL: identifying systemic sclerosis as a unique phenotype. Chest 2010;138:1383-1394.

21. Yang X, Mardekian J, Sanders KN, Mychaskiw MA, Thomas J 3rd. Prevalence of pulmonary arterial hypertension in patients with connective tissue diseases: a systematic review of the literature. Clin Rheumatol 2013;32:1519-1531.

22. Song S, Lee SE, Oh SK, et al. Demographics, treatment trends, and survival rate in incident pulmonary artery hypertension in Korea: a nationwide study based on the health insurance review and assessment service database. PLoS One 2018;13:eo209148.

23. Benza RL, Gomberg-Maitland M, Miller DP, et al. The REVEAL registry risk score calculator in patients newly diagnosed with pulmonary arterial hypertension. Chest 2012;141:354-362.

24. Ogawa A, Ejiri K, Matsubara H. Long-term patient survival with idiopathic/heritable pulmonary arterial hypertension treated at a single center in Japan. Life Sci 2014;118:414-419.

25. Loyd JE, Primm RK, Newman JH. Familial primary pulmonary hypertension: clinical patterns. Am Rev Respir Dis 1984;129:194-197.

26. Deng Z, Morse JH, Slager SL, et al. Familial primary pul- 
monary hypertension (gene $\mathrm{PPH}$ ) is caused by mutations in the bone morphogenetic protein receptor-II gene. Am J Hum Genet 2000;67:737-744.

27. International PPH Consortium, Lane KB, Machado RD, et al. Heterozygous germline mutations in BMPR2, encoding a TGF-beta receptor, cause familial primary pulmonary hypertension. Nat Genet 2000;26:81-84.

28. Evans JD, Girerd B, Montani D, et al. BMPR2 mutations and survival in pulmonary arterial hypertension: an individual participant data meta-analysis. Lancet Respir Med 2016;4:129-137.

29. Morrell NW, Aldred MA, Chung WK, et al. Genetics and genomics of pulmonary arterial hypertension. Eur Respir J 2019;53.

30. ClinicalTrial.gov. Effect of BMPR-2 Gene Mutations on Hemodynamic Response by Iloprost Inhalation in Pulmonary Arterial Hypertension (PILGRIM) [Internet]. Bethesda (MD): U.S. National Library of Medicine, c2019 [cited 2019 Jun 24]. Available from: https://clinicaltrials. gov/ct2/show/NCTo1054105.

31. Sztrymf B, Coulet F, Girerd B, et al. Clinical outcomes of pulmonary arterial hypertension in carriers of BMPR2 mutation. Am J Respir Crit Care Med 2008;177:1377-1383.

32. Liu D, Wu WH, Mao YM, et al. BMPR2 mutations influence phenotype more obviously in male patients with pulmonary arterial hypertension. Circ Cardiovasc Genet 2012;5:511-518.

33. Morisaki H, Nakanishi N, Kyotani S, Takashima A, Tomoike H, Morisaki T. BMPR2 mutations found in Japanese patients with familial and sporadic primary pulmonary hypertension. Hum Mutat 2004;23:632.

34. Austin ED, Phillips JA, Cogan JD, et al. Truncating and missense BMPR2 mutations differentially affect the severity of heritable pulmonary arterial hypertension. Respir Res 2009;10:87.

35. Pfarr N, Szamalek-Hoegel J, Fischer C, et al. Hemodynamic and clinical onset in patients with hereditary pulmonary arterial hypertension and BMPR2 mutations. Respir Res 2011;12:99.

36. Kabata H, Satoh T, Kataoka M, et al. Bone morphogenetic protein receptor type 2 mutations, clinical phenotypes and outcomes of Japanese patients with sporadic or familial pulmonary hypertension. Respirology 2013;18:10761082.

37. Pulido T, Adzerikho I, Channick RN, et al. Macitentan and morbidity and mortality in pulmonary arterial hy- pertension. N Engl J Med 2013;369:809-818.

38. Ghofrani HA, Galie N, Grimminger F, et al. Riociguat for the treatment of pulmonary arterial hypertension. $\mathrm{N}$ Engl J Med 2013;369:330-340.

39. Sitbon O, Channick R, Chin KM, et al. Selexipag for the treatment of pulmonary arterial hypertension. N Engl J Med 2015;373:2522-2533.

40. Galie N, Barbera JA, Frost AE, et al. Initial use of ambrisentan plus tadalafil in pulmonary arterial hypertension. N Engl J Med 2015;373:834-844.

41. McLaughlin VV, Oudiz RJ, Frost A, et al. Randomized study of adding inhaled iloprost to existing bosentan in pulmonary arterial hypertension. Am J Respir Crit Care Med 2006;174:1257-1263.

42. Simonneau G, Rubin LJ, Galie N, et al. Addition of sildenafil to long-term intravenous epoprostenol therapy in patients with pulmonary arterial hypertension: a randomized trial. Ann Intern Med 2008;149:521-530.

43. Tapson VF, Torres F, Kermeen F, et al. Oral treprostinil for the treatment of pulmonary arterial hypertension in patients on background endothelin receptor antagonist and/or phosphodiesterase type 5 inhibitor therapy (the FREEDOM-C study): a randomized controlled trial. Chest 2012;142:1383-1390.

44. Galie N, Brundage BH, Ghofrani HA, et al. Tadalafil therapy for pulmonary arterial hypertension. Circulation 2009;119:2894-2903.

45. Iversen K, Jensen AS, Jensen TV, Vejlstrup NG, Sondergaard L. Combination therapy with bosentan and sildenafil in Eisenmenger syndrome: a randomized, placebo-controlled, double-blinded trial. Eur Heart J 2010;31:1124-1131.

46. Simonneau G, Torbicki A, Hoeper MM, et al. Selexipag: an oral, selective prostacyclin receptor agonist for the treatment of pulmonary arterial hypertension. Eur Respir J 2012;40:874-880.

47. McLaughlin VV, Benza RL, Rubin LJ, et al. Addition of inhaled treprostinil to oral therapy for pulmonary arterial hypertension: a randomized controlled clinical trial. J Am Coll Cardiol 2010;55:1915-1922.

48. Galie N, Rubin Lj, Hoeper M, et al. Treatment of patients with mildly symptomatic pulmonary arterial hypertension with bosentan (EARLY study): a double-blind, randomised controlled trial. Lancet 2008;371:2093-2100.

49. Sitbon O, Jais X, Savale L, et al. Upfront triple combination therapy in pulmonary arterial hypertension: a pilot 
study. Eur Respir J 2014;43:1691-1697.

50. Hassoun PM, Zamanian RT, Damico R, et al. Ambrisentan and tadalafil up-front combination therapy in scleroderma-associated pulmonary arterial hypertension. Am J Respir Crit Care Med 2015;192:1102-1110.

51. Tamura Y, Kumamaru H, Satoh T, et al. Effectiveness and outcome of pulmonary arterial hypertension-specific therapy in Japanese patients with pulmonary arterial hypertension. Circ J 2017;82:275-282.

52. Akagi S, Matsubara H, Nakamura K, Ito H. Modern treatment to reduce pulmonary arterial pressure in pulmonary arterial hypertension. J Cardiol 2018;72:466-472.

53. Tokunaga N, Ogawa A, Ito H, Matsubara H. Rapid and high-dose titration of epoprostenol improves pulmonary hemodynamics and clinical outcomes in patients with idiopathic and heritable pulmonary arterial hypertension. J Cardiol 2016;68:542-547.

54. Ahn KJ, Jang AY, Chung WJ. 15 Years journey of idiopathic pulmonary arterial hypertension with BMPR2 mutation. Clin Hypertens. 2019 In Press.

55. Gaine S, McLaughlin V. Pulmonary arterial hypertension: tailoring treatment to risk in the current era. Eur Respir Rev 2017;26.

56. Buda ES, Hanfore LK, Fite RO, Buda AS. Lifestyle modification practice and associated factors among diagnosed hypertensive patients in selected hospitals, South Ethiopia. Clin Hypertens 2017;23:26.

57. Lee HT, Namgung J, Lim YH, Park HC, Park JK, Shin J. The relationship between visit-to-visit variability in blood pressure and incidence of metabolic syndrome: a general population-based cohort study in Korea. Clin Hypertens 2019;25:11.

58. Sa'adeh HH, Darwazeh RN, Khalil AA, Zyoud SH. Knowledge, attitudes and practices of hypertensive patients towards prevention and early detection of chronic kidney disease: a cross sectional study from Palestine. Clin Hypertens 2018;24:6.

59. Tocci G, Cicero AF, Salvetti M, et al. Attitudes and preferences for the clinical management of hypertension and hypertension-related cerebrovascular disease in the general practice: results of the Italian hypertension and brain survey. Clin Hypertens 2017;23:10.

6o. Mereles D, Ehlken N, Kreuscher S, et al. Exercise and respiratory training improve exercise capacity and quality of life in patients with severe chronic pulmonary hypertension. Circulation 2006;114:1482-1489.
61. Ruiter G, Lankhorst S, Boonstra A, et al. Iron deficiency is common in idiopathic pulmonary arterial hypertension. Eur Respir J 2011;37:1386-1391.

62. Howard LS, Watson GM, Wharton J, et al. Supplementation of iron in pulmonary hypertension: rationale and design of a phase II clinical trial in idiopathic pulmonary arterial hypertension. Pulm Circ 2013;3:100-107.

63. Mirdamadi A, Moshkdar P. Benefits from the correction of vitamin $\mathrm{D}$ deficiency in patients with pulmonary hypertension. Caspian J Intern Med 2016;7:253-259.

64. Brown LM, Chen H, Halpern S, et al. Delay in recognition of pulmonary arterial hypertension: factors identified from the REVEAL registry. Chest 2011;140:19-26.

65. Austin ED, Kawut SM, Gladwin MT, Abman SH. Pulmonary hypertension: NHLBI Workshop on the primary prevention of chronic lung diseases. Ann Am Thorac Soc 2014;11:S178-S185.

66. McLaughlin VV, Langer A, Tan M, et al. Contemporary trends in the diagnosis and management of pulmonary arterial hypertension: an initiative to close the care gap. Chest 2013;143:324-332.

67. Lau EM, Manes A, Celermajer DS, Galie N. Early detection of pulmonary vascular disease in pulmonary arterial hypertension: time to move forward. Eur Heart J 2011;32:2489-2498.

68. Frost A, Badesch D, Gibbs JSR, et al. Diagnosis of pulmonary hypertension. Eur Respir J 2019;53.

69. Hoeper MM, Huscher D, Ghofrani HA, et al. Elderly patients diagnosed with idiopathic pulmonary arterial hypertension: results from the COMPERA registry. Int J Cardiol 2013;168:871-88o.

70. McGoon MD, Miller DP. REVEAL: a contemporary US pulmonary arterial hypertension registry. Eur Respir Rev 2012;21:8-18.

71. Jing ZC, Xu XQ, Han ZY, et al. Registry and survival study in Chinese patients with idiopathic and familial pulmonary arterial hypertension. Chest 2007;132:373-379.

72. Lau EMT, Giannoulatou E, Celermajer DS, Humbert M. Epidemiology and treatment of pulmonary arterial hypertension. Nat Rev Cardiol 2017;14:603-614.

73. Humbert M, Sitbon O, Chaouat A, et al. Survival in patients with idiopathic, familial, and anorexigen-associated pulmonary arterial hypertension in the modern management era. Circulation 2010;122:156-163.

74. Ling Y, Johnson MK, Kiely DG, et al. Changing demographics, epidemiology, and survival of incident pulmo- 
nary arterial hypertension: results from the pulmonary hypertension registry of the United Kingdom and Ireland. Am J Respir Crit Care Med 2012;186:790-796.

75. Delude CM. Deep phenotyping: the details of disease. Nature 2015;527:S14-S15.

76. Purkait P, Halder K, Thakur S, et al. Association of angiotensinogen gene SNPs and haplotypes with risk of hypertension in eastern Indian population. Clin Hypertens 2017;23:12.

77. Soubrier F, Chung WK, Machado R, et al. Genetics and genomics of pulmonary arterial hypertension. J Am Coll Cardiol 2013;62:D13-D21.

78. PAH Biobank. Home [Internet]. Cincinnati (OH): Nation- al Biological Sample and Data Repository for PAH, c2019 [cited 2019 Jun 1]. Available from: https://www.pahbiobank.org/.

79. Cambridge Biomedical Research Center. Home [Internet]. Cambridge (UK): National Institute for Health Research, c2019 [cited 2019 Jun 1]. Available from: https://bridgestudy.medschl.cam.ac.uk/pah.shtml.

8o. Kim S, Jang AY, Chung WJ, et al. A nationwide multicenter registry and biobank program for deep phenotyping of idiopathic and hereditary pulmonary arterial hypertension in Korea: the PAH Platform for Deep Phenotyping in Korean Subjects (PHOENIKS) Cohort. Clin Hypertens. 2019 In Press. 